\title{
AS CATEGORIAS TRABALHO (MARX) E HUMANIZAÇÃO (FREIRE): Implicações no Currículo "São Paulo Faz Escola"
}

\author{
LAS CATEGORÍAS TRABAJO (MARX) Y HUMANIZACIÓN (FREIRE): \\ Implicaciones en el currículo "São Paulo Faz Escola"
}

\section{THE WORK (MARX) AND HUMANIZATION (FREIRE) CATEGORIES: Implications in the São Paulo Curriculum does School}

Aldo Abitante ${ }^{1}$

https://orcid.org/0000-0002-2561-1444

Renata Reis dos Santos ${ }^{2}$ https://orcid.org/0000-0002-9877-7293

Juliana Rezende Torres 3 https://orcid.org/0000-0002-4598-6702

Antônio Fernando Gouvêa da Silva ${ }^{4}$ https://orcid.org/0000-0002-8915-9952

\section{Resumo:}

Este trabalho parte das discussões realizadas pelo Grupo de Pesquisa Teorias e Fundamentos da Educação (GPTeFE / UFSCar) com base na análise do "currículo "São Paulo Faz Escola"" (20082018). A partir de uma suposta perspectiva humanista presente na proposta curricular, analisa-se quais seriam as possíveis aproximações e distanciamentos em relação ao entrelaçamento teórico das categorias "Humanização" para Freire e "Trabalho" em Marx. Para tanto, buscou-se estabelecer articulações epistemológicas e ontológicas entre as duas categorias a partir de

\footnotetext{
${ }^{1}$ Mestre em Educação pelo Programa de Pós Graduação em Educação da Universidade Federal de São Carlos - Campus Sorocaba, E-mail: aldoabitante1981@outlook.com

${ }^{2}$ Mestra em Educação pelo Programa de Pós Graduação em Educação da Universidade Federal de São Carlos - Campus Sorocaba. E-mail: renata.reis@ifsp.edu.br

3 Docente permanente do Programa de Pós-Graduação em Educação da Universidade Federal de São Carlos - Campus Sorocaba, E-mail: julianart@ufscar.br

${ }^{4}$ Docente de Ensino Superior, Graduação e Pós-Graduação, na Universidade Federal de São Carlos, Campus Sorocaba e na Pós-Graduação da Universidade Federal de Santa Catarina, E-mail: gova@uol.com.br
}

\section{Como referenciar este artigo:}

ABITANTE, A.; SANTOS, R. R.; TORRES, J. R.; SILVA, A. F. G. As Categorias Trabalho (Marx) e Humanização (Freire): Implicações no Currículo "São Paulo Faz Escola". Revista Pedagógica, v. 23, p. 1-17, 2021. 
fundamentos teóricos presentes em diferentes obras dos dois autores. Utiliza-se como método a pesquisa bibliográfica e análise documental. A análise crítica do documento manifestou um afastamento das concepções de humanização (Freire) e trabalho (Marx), evidenciando que o currículo implementado afasta-se da práxis dialética desenvolvida pelos autores na relação homens e mundo, negando a historicidade humana, e, desta maneira, acaba por orientar para uma educação voltada a moldar espíritos humanos a necessidades empresariais alinhandos à concepção concepção liberal de trabalho.

Palavras chaves: currículo São Paulo Faz Escola. Humanização. Freire. Trabalho. Marx.

\title{
Resumen:
}

Este trabajo es parte de las discusiones realizadas por el Grupo de Investigación en Teorías y Fundamentos de la Educación (GPTeFE / UFSCar) a partir del análisis del currículo "São Paulo Faz Escola" (2008-2018). A partir de una supuesta perspectiva humanista presente en la propuesta curricular, analizamos cuáles serían las posibles aproximaciones y distancias en relación al entrelazamiento teórico de las categorías "Humanización" para Freire y "Trabajo" en Marx. Así, se buscó establecer articulaciones epistemológicas y ontológicas entre las dos categorías a partir de fundamentos teóricos presentes en diferentes trabajos de los dos autores. Se utiliza como método la investigación bibliográfica y el análisis documental. El análisis crítico del documento mostró un alejamiento de los conceptos de humanización (Freire) y trabajo (Marx), mostrando que el currículo implementado se aleja de la praxis dialéctica desarrollada por los autores en la relación entre el hombre y el mundo, negando la historicidad humana, y de esta manera, termina por orientar hacia una educación orientada a amoldar el espíritu humano a las necesidades empresariales en línea con la concepción liberal del trabajo.

Palabras clave: currículum São Paulo Hace Escuela. Humanización. Freire. Trabajo. Marx.

\begin{abstract}
:
This work is part of the discussions carried out by the Research Group Theories and Fundamentals of Education (GPTeFE / UFSCar) based on the analysis of the curriculum "São Paulo Faz Escola" (2008-2018). From a supposed humanist perspective present in the proposal's curriculum, it analyzes the possible approaches and distances in relation to the theoretical intertwining of the categories "Humanization" for Freire and "Work" in Marx. Thus, we sought to establish epistemological and ontological articulations between the two categories based on theoretical foundations present in different works by the two authors. Bibliographic research and document analysis are used as a method. The critical analysis of the document showed a departure from the concepts of humanization (Freire) and work (Marx), showing that the implemented curriculum moves away from the dialectic praxis developed by the authors in the relationship between man and the world, denying human historicity, and, in this way, ends up orienting itself towards an education aimed at molding the human spirit to the needs of business in line with the liberal conception of work.
\end{abstract}

Key words: curriculum. "São Paulo makes school”. Humanization. Freire. Work. Marx

\section{INTRODUÇÃO}


Muito se tem discutido sobre o conceito de educação e trabalho, evocando este como um princípio educativo no processo humanizador dos homens. Assim, este artigo surge de reflexões acerca dessa temática, dispontadas, principalmente, através de uma análise realizada anteriormente acerca do Currículo do Estado de São Paulo5, na qual questionamos em que medida tal documento estabelece uma articulação com a categoria “trabalho" presente na obra de Marx e o conceito de "humanização" presente nas obras de Freire.

Na encruzilhada das visões de mundo, a concepção da constituição do ser humano se encontra nas divergências do campo de disputas epistêmicas, reflexo dos interesses envolvidos em função dos conflitos entre as classes sociais, assim, o currículo acaba incorporando, também, essa ressonância das disputas (MOREIRA; SILVA, 2002).

Olhando para o centro dessa encruzilhada de fundamentos conceituais, temos, por outro lado, a visão liberal acerca da formação do ser de homens e mulheres, em que a composição do humano nas pessoas se daria em âmbito individual, de forma metafísica, por meio do intelecto. O ser pertencente ao humano se consolidaria por meio das experiências diversas, formando, assim, uma biografia (KERSTING, 2005).

Para o liberalismo contemporâneo de Kersting (2005), a sociedade influencia o ser humano na formação de sua identidade pelo âmbito cultural e por meio da capacidade de reflexão os indivíduos. Segundo essa perspectiva, os seres humanos não são arrastados pelas circunstâncias de vida naturais e sociais preexistentes - entendidas como obstáculos à realização individual. Desta maneira, haveria um nexo direto entre a posse de recursos materiais e a capacidade intelectual de pensar.

Do lado contrário a este entendimento da formação humana, temos em Marx uma concepção ontológica estabelecida entre a relação das pessoas e as circunstâncias de vida (naturais e sociais) preexistentes no processo de construção da humanidade.

No materialismo marxiano prevalece sobre qualquer visão de mundo idealista, o conceito de que toda ação humana se estabelece a partir das condições materiais. Essa atividade do homem fundamenta o conhecimento que historicamente se cumula e, por sua

\footnotetext{
${ }^{5}$ Trabalho parte das discussões realizadas pelo Grupo de Pesquisa Teorias e Fundamentos da Educação (GPTeFE), o qual se dedica a problematização da pesquisa e a busca por saber qual é a incidência da noção de trabalho na concepção e na prática de docentes da rede com um duplo objetivo: um científico e outro educativo.
} 
vez, dá base à atividade posterior a construção desse conhecimento, o que, também, a partir da sua compreensão, leva à novas ações - o que se categoriza como práxis (MAFRA; CAMACHO, 2017).

Segundo Lessa (2001), o conceito de práxis supera qualquer dimensão transcendente. Logo, Marx defende que é através da dialética entre homens e mulheres com o mundo à sua volta que se estabelece o processo de humanização, pois, no momento em que estes buscam atender suas necessidades mais imediatas, transformam a natureza e também a si próprios. Essa transformação se opera através do trabalho das pessoas e resulta, por meio da atividade do trabalho, no plano objetivo e subjetivo, em "algo novo".

Objetivamente, esse "novo" se dá pelo surgimento de uma instrumentalização do meio natural em favor dos indivíduos, humanizando o mundo. Subjetivamente, ao explorar o mundo, as pessoas desenvolvem suas capacidades humanas para a reprodução social.

Como aponta Lessa (2001), é pela reprodução social, a partir do momento em que um indivíduo conhece os mecanismos de produção de uma ferramenta, que os seres humanos desenvolvem sua coletividade. Ao aprender esse mecanismo, o homem também se modifica ao incorporar possibilidades e necessidades que não possuíam antes. Desta maneira, a objetivação de um novo instrumento cria uma circunstância sócio-histórica nova e, no momento em que um grupo adquire o saber sobre a manufatura de uma determinada matéria-prima, explorará essa mesma capacidade para atender outras necessidades nos mais variados campos da práxis social. Assim, o mesmo grupo que aprendeu o uso da pedra e da madeira para produção de um machado, passa a fazer enxada, casas, etc. criando a cultura, a historicidade e a humanização do grupo social e do meio em que vivem.

Uma vez que a essência humana, em Marx, se dá na dialética entre homens e mulheres com o mundo que os cercam, não pode haver um modelo de humano "acabado". Isto porque há uma intrínseca processualidade na formação do ser humano, em sua essência genealógica e em sua formação enquanto ser histórico, que o torna propriamente humano. Essa essencialidade biológica só pode se desenvolver pela mediação através de um fenômeno histórico, havendo uma constante interação entre as duas categorias, em que a essência humana pode "ser profundamente transformada pelo fenômeno [...], por exemplo, em um processo revolucionário [...] que traz em si o novo a ser realizado pela história, superando todas as concepções ontológicas anteriores” (LESSA, 2001, p. 94). 
Portanto, o fazer humano do trabalho é o processo pelo qual a concepção materialista histórica-dialética entende que os homens e as mulheres se fazem humanos na dialética entre suas necessidades e o mundo. De modo que, ao enfrentarem suas necessidades perante a oposição do mundo, desenvolvem suas potencialidades e suas capacidades e, assim, tornam-se seres para si na medida que realizam trabalho para si (LESSA, 2001). Logo, temos que o trabalho é um processo educativo da formação do homem como ser humano (MARX, 2013).

No entanto, ao observar a sociedade capitalista do séc. XVIII, Marx percebe a relação contrária ao processo de humanização pelo trabalho, a alienação. Ou seja, ao se estabelecerem as bases da propriedade e do emprego de mão de obra alheio a quem deteria os meios de produção e os frutos laborativos, a atividade humana de trabalho cria seu duo negativo, que é a negação dos homens (ENGELS, 1984). Essa negação acaba por se valer de discursos fatalistas a-históricos, como os pensados por Kersting (2005), e consistem na perda do fruto produtivo do trabalho e de seu processo de produção, o que resulta no esvaziamento da conscientização que emerge da atividade laboral.

Então, ao se fazer uma análise curricular, buscou-se avaliar se sua proposta se estabelece a partir de um projeto humanizador, ou se, ao contrário, o nega. E assim, ao invés de se tornar um mecanismo de compreensão dos processos históricos que impedem dos educandos tornarem-se humanos, o currículo reforçaria narrativas ideológicas que os situariam na acomodação do processo de alienação.

No que diz respeito à educação humanizadora, Paulo Freire (1987) propõe uma pedagogia emancipatória, que tem como objetivo a igualdade e a justiça social, de maneira a comprometer-se com a luta contra qualquer forma de desumanização, por meio do processo educativo que busca superar a desumanização para restabelecer a vocação ontológica dos indivíduos em "ser mais".

Freire abarca na categoria ser mais a ontologia do ser humano em seu processo constante de constituição/ em uma dialética materialista e histórica em que homens e mulheres experimentam a partir da sua consciência e superação (conscientização) dos condicionamentos e situações limites que os oprimem como seres humanos. Esse processo de luta pela afirmação e conquista da liberdade, em sua historicidade, se dá por meio das 
tensões entre as vivências da opressão e a práxis transformadora que as pessoas se lançam para a procura de uma experiência concreta de humanização

Desta maneira, em consonância com as ideias de Marx - que estabelece que a instância do trabalho não alienado é o processo educativo natural pelo qual o homem aprende suas potencialidades no confronto dos limites dados pelo mundo para atender suas necessidades —, o processo educativo segundo Freire se projeta para evidenciar as situações-limites com o educando e tende a impulsioná-los para a ação da superação de suas opressões, fazendo um duplo movimento de transformação da realidade.

Desta maneira, o processo educativo nesta perspectiva se dá numa dupla atividade de trabalho marxista: a de desvelamento da realidade, que transforma o mundo das consciências e os homens nelas imersos; e da práxis resultante deste desvelamento, que transforma o mundo material da opressão por meio da ação transformadora (FREIRE, 1987).

\section{CURRÍCULO "SÃo PAULO FAZ ESCOLA" — UMA BREVE APRESENTAÇÃO}

Para entendermos como se articula o conceito de trabalho dentro do projeto "São Paulo Faz Escola", que resultou na proposta curricular desse estado no ano de 2008, coloca-se aqui uma breve trajetória de sua constituição e como este currículo expõe este conceito.

O percurso do "São Paulo Faz Escola" se inicia com reformas educacionais estabelecidas em 2008, ano em que a Secretaria de Educação do Estado de São Paulo realizou um projeto que propunha um novo currículo para as escolas de Ensino Fundamental II e Médio, por meio da Resolução da Secretaria da Educação número 98, sob o discurso de uma "busca na melhoria da qualidade das aprendizagens de seus alunos" (SÃO PAULO, 2008).

A partir da Proposta Curricular Paulista, sob encargo da Secretaria da Educação do estado foram elaborados "cadernos" (material apostilado) por intermédio da Fundação Vanzolini.

Impresso sob a forma de jornais para os alunos e em revistas para os professores, o material seria distribuído, de forma provisória, para os primeiros 42 dias letivos, com a finalidade de que fossem avaliados os conteúdos e que os professores realizassem 
apontamentos e modificações do material, antes da versão definitiva. A maior reclamação dos professores, entretanto, foi em relação ao papel e ao formato de jornal adotado por serem de difícil manejo, havendo pouca divergência no conteúdo ali positivado (CATANZARO, 2012).

Esse processo, segundo Catanzaro (2012), teria partido de diagnósticos “dos resultados de avaliações externas do ano de 2007, como o SAEB (hoje Prova Brasil), o Enem e outras avaliações", embocando na implantação do currículo "São Paulo Faz Escola".

Historicamente, o que vinha ocorrendo não só no Brasil, mas em toda a América Latina, era um processo de submissão a um pacto de políticas internacionais com a finalidade de obter financiamentos com capital de bancos de fomento estrangeiro. Essas negociações foram feitas a fim de realizar ajustes macroeconômicos com o propósito de enfrentamento da inflação e da estagnação econômica. Entretanto, para que fossem liberadas essas verbas era necessário que os países desenvolvessem políticas públicas para ampliar seus sistemas de ensino e adequá-los as demandas de mercado (DELUIZ, 2001).

\begin{abstract}
Na América Latina o modelo das competências surge no bojo das reformas educacionais, que por sua vez são parte do conjunto de reformas estruturais no aparelho do Estado. Estas reformas são decorrentes do ajuste macroeconômico ao qual os países latino-americanos se submeteram ao longo dos anos 90, para superar a inflação e a estagnação e retomar o crescimento econômico interrompido na década perdida de 80 [....]. No contexto do ideário neoliberal de despolitização da economia, de desregulação do mercado financeiro e do trabalho, do desmonte do Estado de Bem-Estar Social e do pacto fordista - as reformas educacionais, realizadas sob a orientação e apoio financeiro de organismos internacionais (BID, BIRD, UNESCO, OIT), 14 começaram a tomar forma no Brasil dos anos 90 (DELUIZ, 2001, p. 5).
\end{abstract}

O então Governo do Estado de São Paulo, do partido PSDB, alinhado com o Governo Federal, do mesmo partido, apresentou nova proposta pedagógica, sob discurso de se tratar de um enfrentamento perante as desigualdades de acesso aos bens culturais geradas em relação as novas demandas e avanços tecnológicos da globalização no século XXI (SÃO PAULO, 2008-a). Esta proposta surge, então, para atender as demandas legais (Lei de Diretrizes e Bases 9394/96) e solicitações do Banco Interamericano de Desenvolvimento (BIRD) - que para financiar projetos nos ditos países em desenvolvimento, exigia, pela "Conferência Mundial sobre Educação para Todos", índices que demonstravam avanços estatístico na educação. 
No entanto, esse currículo era, de fato, um ajuste não só com as imposições dos órgãos estrangeiros de fomento, mas também apresentava "princípios privatistas e mercantilistas dos empresários preocupados como novo mundo em globalização, que demandavam novas competências de seus trabalhadores" (CATANZARO, 2012, p. 69).

Essas imposições podem ser sentidas no que diz respeito ao alinhamento da proposta curricular com as demandas de mercado face a chamada "crise do fordismotaylorismo" para a adequação de uma "nova" organização coorporativa que se difundiu pelo mundo em meados da década de 1970 e se estabilizou em grande parte das empresas brasileiras da década de 90 - o modelo de acumulação flexível, também conhecido como toyotismo (ALVES, 2008).

Para se apreender esse posicionamento da Proposta Curricular de São Paulo em conformidade com o pensamento toyotista, vale ressaltar alguns dos seus principais pontos que encontram essa ressonância, levantando-se aqui, em primeiro lugar, as notas que compõem essa organização da produção mundial.

Segundo Egoshi (2009), sob o lema do "Kaizen” (do japonês “melhoria”), o toyotismo é uma combinação entre a cultura japonesa e os conhecimentos de management norte-americano, que foram se incorporando a partir dos anos 50, no período de industrialização do Japão.

Para descrever essa miscigenação cultural e organizacional, este autor faz um panorama geral sobre a administração toyotista afirmando que, em uma empresa, a qualidade está a encargo de todos seus membros, e seu administrador deve ter um olhar sistêmico do todo e das partes, para que não ocorram "subotimizações", buscando o controle total de qualidade. Nesta maneira de gerenciamento de negócios "é tão importante fazer bem feito (eficiência) quanto obter o resultado certo (eficácia)" (EGOSHI, 2009, p. 2).

Nesta concepção de gerenciamento empresarial exposta por Egoshi (2009), é imposta a forma colaborativa para a execução de tarefas; e essas pessoas, que compõem o quadro de funcionários, devem estar emocionalmente equilibradas para aumentar a produtividade. É importante que o “Grupo de trabalho" se mantenha estável pelo entendimento de que a preservação da situação financeira do empregado reflete diretamente no seu emocional e, portanto, na sua produtividade. 
Como descreve o autor, o clima da organização deve ter uma aparente harmonia, nem que isso signifique uma "forçada na barra"; logo, todos devem estar em consonância no trabalho, com a evidência de um caráter de ordem, disciplina e subordinação. Evitando tudo aquilo que se considera desnecessário para a rotina de trabalho ou que atrapalhe a produtividade do "colaborador".

Pelo o que Egoshi (2009) retrata do toyotismo, temos que concordar com Alves (2008, p. 63) que afirma que esta forma organizacional demanda a necessidade de "um intenso nexo psicofísico, a unidade orgânica entre ação e pensamento no local de trabalho como uma das pré-condições do próprio desenvolvimento da nova materialidade do capital”. Assim, para Alves (2008, p. 64): “Enquanto que no taylorismo fordismo, como observou Gramsci, 'só o gesto físico mecanizou-se inteiramente', no toyotismo, a “mecanização” atinge corpo e mente do homem produtivo".

Assim, pode-se deduzir a intencionalidade da articulação dos conteúdos escolares com a "contextualização no mundo do trabalho" (SÃO PAULO, 2008), conforme explicitado pelo projeto "São Paulo Faz Escola", sendo que o termo "trabalho" foi colocado no documento na acepção de emprego das forças humanas para transformação da matéria, com fins de geração de riqueza (SILVA, 2011).

Assim, para que se efetivasse essa incorporação do conceito de trabalho liberal na concepção do currículo do estado de São Paulo, adotou-se o princípio de pedagogia das competências. Segundo Deluiz (2001), a escolha de competências se dá sob a fundamentação epistemológica de análise experimental do comportamento, que tem relação direta com as necessidades do mercado liberal e que pode ser treinada.

Dessa forma, nosso objetivo principal é compreender em que local desta encruzilhada de conflitos epistemológicos como materialização da luta de classes sociais, o currículo do Estado de São Paulo se encontra. Ou seja, o que se buscará compreender são as proximidades e afastamentos entre um projeto de humanização na concepção marxista, e em que medida o currículo em questão se aproxima de um modelo idealizado de homem dado pelo liberalismo, negando-lhe a possibilidade sua humanização como processo de luta histórica.

Também se pretende discutir a contraposição estabelecida por Freire, no que tange o processo de Humanização/Desumanização, e como a sua superação aponta para a 
necessidade de uma pedagogia libertadora, que surge da análise que o ser humano faz de seu próprio processo de humanização.

A metodologia adotada para a realização dessa pesquisa foi exclusivamente pesquisa bibliográfica: revisão da literatura e análise documental. Segundo Severino (2016, p. 13), a pesquisa bibliográfica é aquela que é realizada a partir de um registro disponível, com dados das categorias teóricas já trabalhadas por outros pesquisadores e devidamente registradas. A pesquisa documental pode ser conceituada considerando as fontes de documentos no sentido amplo, ou seja, os conteúdos dos textos que ainda não tiveram tratamento analítico e são, ainda, matéria prima sobre a qual o pesquisador vai desenvolver sua investigação e análise.

Considerada uma técnica decisiva para pesquisas nas áreas das Ciências Sociais e Humanas, a análise documental é indispensável, pois a maior parte das fontes escritas ou não, são quase sempre a base do trabalho de investigação. Realiza-se a partir de documentos contemporâneos ou retrospectivos considerados autênticos.

O percurso metodológico se deu a partir da seleção de recortes da obra "O Capital" de Karl Marx sobre "trabalho", bem como recortes da obra "Pedagogia do Oprimido" de Paulo Freire sobre "humanização". Tais verbetes “trabalho" e "humanização” serviram de referencial teórico-metodológico para verificar se o currículo do estado de São Paulo corresponde a tais categorias.

\section{POSSÍVEIS IMPLICAÇÕES NO CURRÍCULO "SÃO PAULO FAZ ESCOLA" A PARTIR DAS RELAÇÕES ENTRE AS CATEGORIAS DE TRABALHO EM MARX E HUMANIZAÇÃO EM FREIRE}

A partir da exposição do currículo "São Paulo Faz Escola" e do referencial teórico, apresentamos as proximidades e distanciamentos entre o referido currículo e as categorias trabalho em Marx (2013) e humanização em Freire (1987).

O currículo em questão, logo em sua apresentação, posiciona-se no sentido de se orientar a fim de preparar os alunos para enfrentar os "desafios sociais" do mundo contemporâneo. Estes desafios são compreendidos pelo documento como uma adequação entre a demanda do mercado de trabalho e para que a escola produza jovens com perfis "sociais, culturais e profissionais" adequados a essa demanda e, sendo assim, o 


\title{
REVISTA
}

\section{Revista do Programa de Pós-Graduação em Educação da Unochapecó ISSN 1984-1566 (on-line) ISSN 1415-8175 (impressa)}

ensino-aprendizagem deve relacionar o conhecimento escolar ao trabalho que o aluno exerce ou potencialmente exercerá (SÃO PAULO, 2008, p.16).

Por isso, há um pragmatismo que o currículo enseje o mais breve o possível o jovem para o mercado de trabalho. Assim, aquilo que deve fazer parte do currículo, segundo a proposta do governo do estado de São Paulo é:

A relevância e a pertinência das aprendizagens escolares nessas instituições são decisivas para que o acesso a elas proporcione uma oportunidade real [...] para inserção no mundo de modo produtivo e solidário (SÃO PAULO, 2008, p. 5).

Em outro trecho, o currículo evidencia que a implicação pedagógica adotada em sua fundamentação visa ressaltar o trabalho humano, de forma que a teoria e a prática estejam relacionadas em seu conteúdo e que sejam consideradas relevantes todas as carreiras profissionais.

\begin{abstract}
A implicação pedagógica desse princípio atribui um lugar de destaque para o trabalho humano, contextualizando os conteúdos curriculares sempre que for pertinente, com os tratamentos adequados a cada caso. Nesse sentido, a relação entre teoria e prática em cada disciplina do currículo, como exige a lei, não pode deixar de incluir os tipos de trabalho e as carreiras profissionais (SÃO PAULO, 2008, p. 18).
\end{abstract}

Entretanto, ao adotar essa perspectiva de trabalho (como mão de obra a serviço de empresas), evidencia-se uma dupla negação ao se considerar uma perspectiva educativa emancipatória. Isto porque essa educação se projeta com o fim de incluir o aluno no universo da opressão (FREIRE, 1987), uma vez que o educando, ao ser incorporado no mercado de trabalho vendendo a sua mão de obra, acaba por ser absorvido no processo de alienação do trabalho e de seu espírito (MARX, 2013).

Desta maneira, o currículo "São Paulo Faz Escola”, caminha em direção oposta da concepção de Freire sobre a educação, que é estabelecida pela "luta pela humanização, pelo trabalho livre, pela desalienação, pela afirmação dos homens como pessoas, como "seres para si" (FREIRE, 1987, p. 16).

Como visa atender a demanda do mercado de trabalho toyotista, em que o comportamento do funcionário é parte essencial do funcionamento organizacional, o texto coloca que a formação do ser humano se dá por meio do desenvolvimento da 
capacidade de agir, advindas da aprendizagem independente dos saberes historicamente acumulados e por meio da aprendizagem da solidariedade.

O desenvolvimento pessoal é um processo de aprimoramento das capacidades de agir, pensar, atuar sobre o mundo [...]. Esse tipo de educação constrói, de forma cooperativa e solidária, uma síntese dos saberes produzidos pela humanidade [...]. A autonomia para gerenciar a própria aprendizagem (aprender a aprender) é o resultado dela em intervenções solidarias (aprender a fazer e a conviver) deve ser a base da educação das crianças, dos jovens e dos adultos. (SÃO PAULO, 2008, p. 6).

Porém, ao afirmar que a formação humana se dá através dos saberes historicamente acumulados, reafirma uma prática educativa já denunciada por Paulo Freire - a educação bancária - que "nega a dialogicidade como essência da educação e se faz antidialógica" (FREIRE, 1987, p. 44). Ao centrar as prescrições educativas no acúmulo dos saberes já previamente constituídos, não permite a dialética entre os educandos e a realidade que os cerca, para que possam fazer o desvelamento das situações que os desumanizam e modificarem a situação de opressão.

Se não é disposta aos educandos uma educação que os confrontem a realidade e, ao invés disso, lhes é posto um currículo que os levem a aceitar os saberes produzidos pela humanidade como verdades irrefutáveis, como podem modificar a si e ao mundo que os cercam se não há uma dialética entre homens e mundo? Seria impossível. "Daí que a "educação bancária", que a eles serve, jamais possa orientar-se no sentido da conscientização dos educandos" (FREIRE, 1987, p. 39)

Como para a organização empresarial de modelo japonês a habilidade socioemocional é tão importante, essa competência é ressaltada pelo currículo "São Paulo Faz Escola" que projeta uma serie de competências a serem alcançadas nessa proposta de formação do educando enquanto ser humano:

Do ponto de vista social e afetivo, a centralidade da linguagem nos processos de desenvolvimento possibilita ao adolescente aprender, pouco a pouco, a considerar suas escolhas em uma escala de valores. Viabiliza lhe aprender a enfrentar as consequências das próprias ações, a propor e alterar contratos, a respeitar e criticar normas, a formular seu próprio projeto de vida e a tecer seus sonhos de transformação do mundo (SÃO PAULO, 2008, p. 12). 
Ora, se fosse possível formar homens e mulheres pelo processo educativo, depois de concluído o processo de educação, os educandos estariam formados e, portanto, "prontos" do ponto de vista ontológico.

Mas ao negar a inconclusão dos homens, o currículo "São Paulo Faz Escola" acaba por se tornar um instrumento à serviço da desumanização, por impor um discurso negador da vocação ontológica do "ser mais". Distorcendo ideologicamente a possibilidade histórica dos homens, nada mais teríamos que fazer, a não ser aceitar que a alienação do ser humano perante ao mercado de trabalho seria inevitável e, por isso, deveria ser a função da escola "formar" seus alunos para esse "único" caminho, "em que a luta das pessoas, como "seres para si”, não teria significação (FREIRE, 1987, p. 19). Por isso que a concepção e a prática "bancária", imobilista, "fixista", termina por desconhecer os homens como seres históricos, enquanto a educação problematizadora parte exatamente do caráter histórico e da historicidade dos homens (FREIRE, 1987, p. 47).

Esse ensino de competência se coloca bem claro enquanto habilidade a serviço de resolução de problemas, pois, ao contrário da proposta de Freire que entende a leitura do mundo como início da práxis para transformação do mundo, a Proposta Curricular do Estado de São Paulo, aponta que essas competências servem apenas como ferramenta de explicar os problemas e apontar caminhos para a adequação a eles.

\footnotetext{
É com essas competências e habilidades que ele contará para fazer sua leitura crítica do mundo, para compreendê-lo e propor explicações, para defender suas idéias e compartilhar novas e melhores formas de ser, na complexidade em que hoje isso e requerido. E com elas que, em síntese, ele poderá enfrentar problemas e agir de modo coerente em favor das múltiplas possibilidades de solução ou gestão. [...] Competências, neste sentido, caracterizam modos de ser, raciocinar e interagir que podem ser depreendidos das ações e das tomadas de decisão em contextos de problemas, tarefas ou atividades (SÃO PAULO, 2008, p. 9).
}

Em muitas vezes o termo "crítico" é colocado em situações de anfibolia e seu sentido é empregado de forma ideológica. Neste caso, na acepção que nos coloca Marilena Chauí, como a construção de um pensamento coletivo construído por um processo histórico-social-político para ocultar a situação concreta de exploração econômica, desigualdade social e opressão (CHAUÍ, 2008).

Podemos notar isso, por exemplo, em:

Um currículo referido a competências supõe que se aceite o desafio de promover os conhecimentos próprios de cada disciplina articuladamente às competências e habilidades do aluno. É com essas competências e habilidades que ele contará 
para fazer sua leitura crítica do mundo, para compreendê-lo e propor explicações, para defender suas ideias e compartilhar novas e melhores formas de ser, na complexidade em que hoje isso é requerido" (SÃO PAULO, 2008-a, grifo nosso).

A expressão "suas ideias", como está construída na frase, dá margem para ambiguidade de sentido, uma vez que o pronome "suas" pode fazer referência tanto à palavra "mundo" quanto à aluno.

Isso se sobressalta ao se fazer uma busca no texto combinando a expressão "pensamento crítico", que está ausente no texto. Quase não se encontra a expressão "pensamento crítico"; o que aparece geralmente acompanhando a palavra "crítico", é a palavra "respeito".

O aluno precisaria constituir as competências para reconhecer, identificar e ter visão crítica daquilo que é próprio de uma área de conhecimento, e, a partir desse conhecimento, avaliar a importância dessa área ou disciplina em sua vida e em seu trabalho. No entanto, o espírito crítico aqui é colocado apenas para o aluno identificar se o conteúdo que lhe está sendo transmitido tem importância para um eventual futuro trabalho.

Portanto, o que se pode notar, a partir de uma leitura deste currículo que leve em consideração a comparação do referencial teórico de Marx e Freire, é que a proposta curricular do programa "São Paulo Faz Escola" trabalha para a inserção na opressão, afastando-se completamente da questão de "trabalho" em Marx e "humanização" de Freire.

\section{CONSIDERAÇÕES FINAIS}

Ao tomarmos como referencial teórico a relação conceitual entre a definição marxista de trabalho e a ideia educativa de humanização, nota-se que ambas convergem para um mesmo movimento: a práxis de transformação de uma dada realidade para tornála menos hostil.

Assim como em Marx - em que a mudança do mundo se dá pela necessidade e se faz como um processo educativo, no sentido de possibilitar aos seres humanos exercerem sua capacidade de explorar e incorporar socialmente as suas potencialidades em atividades no momento em que estão agindo no mundo que os cerca - em Freire, o processo 
educativo se dá na busca da transformação do mundo pelo desvelamento das necessidades. Este processo, por ser educativo e dialógico, conduz os homens ao embate com as suas realidades opressoras por eles desveladas. Assim, passado o momento do desvelamento, tornam-se motores históricos os princípios que levam aos homens e mulheres no caminho de transformarem-se em mais humanos e humanizarem o mundo a sua volta.

São, portanto, caminhos que convergem no mesmo ponto - a emancipação do homem - e divergem do mesmo sentido - a alienação, que ao separar o homem do fruto de seu trabalho e dos meios produtivos que permitem a realização da criação desses produtos que lhes são necessários, acaba por afastar-lhes de suas consciências (MARX, 2013). Consciência que quando apartada do homem, o faz cair nas sendas dos discursos ideológicos da aceitação de sua condição de "quase coisa" e, assim, acomodam seus espíritos nas condições alienantes de vida — o que faz com que recaia sobre os homens e mulheres a usurpação de suas naturezas, de serem quem são - o que os insere no mundo da opressão (FREIRE, 1987).

Assim, perante ao quadro de opressão e alienação, o que se espera de um processo educativo, ao se tomar a mesma perspectiva de Marx e Freire, seria essa busca pela humanização através da ação modificadora do mundo da opressão.

Porém, ao perceber um alinhamento teórico e metodológico em um currículo oficial o que se observa é que, com base em um discurso ideológico para proporcionar ao educando a empregabilidade, faz-se um instrumento de acondicionamento dos espíritos humanos para a aceitação da opressão.

Neste aspecto, o que o currículo "São Paulo Faz Escola" denota em uma leitura crítica é que ele foi produzido e implementado com o objetivo de acomodar corpos e seus espíritos humanos à negação de suas próprias necessidades e à adequação de demandas de entes despersonalizados como "o mercado", "a economia”, “a produtividade”, “o emprego" - e que, na verdade, servem de máscara para esconder a ganância de alguns em detrimento da condição de vida de muitos.

Além do mais, vindo em um discurso pronto e delimitador de paradigmas e de conteúdo, nega a dialogicidade tão necessária ao desvelamento da realidade, à práxis e a 
Revista do Programa de Pós-Graduação em Educação da Unochapecó

ISSN 1984-1566 (on-line) ISSN 1415-8175 (impressa)

superação das situações limitantes dos educandos. Assim, negando a necessidade dos homens, nega-lhes a vocação de ser e de "ser mais".

\section{REFERÊNCIAS}

ALVES, Giovanni. Trabalho e subjetividade: o metabolismo social da reestruturação produtiva do capital. Marília: UNESP, 2008.

CATANZARO, Fabiana O. O programa São Paulo Faz a Escola e suas apropriações no cotidiano de uma escola de ensino médio. 2012. Tese de Doutorado. Universidade de São Paulo.

DELUIZ, Neise. O modelo das competências profissionais no mundo do trabalho e na educação: implicações para o currículo. Boletim técnico do Senac, v. 27, n. 3, p. 13-25, 2001.

EGOSHI, Koiti. Os $5 \mathbf{S}$ da Administração Japonesa. Artigo Disponível em: http://www. infobibos. com/Artigos/2006_2 S, v. 5, 2012.

ENGELS, Friedrich. A origem da família, da propriedade privada e do Estado. 9.ed. Civilização Brasileira, 1984.

FREIRE, Paulo. Extensão ou Comunicação? Tradução Rosiska Darcy de Oliveira. 7. ed. Rio de Janeiro, Paz e Terra, 1983.

FREIRE, Paulo. Pedagogia do Oprimido. 17 ed. Rio de Janeiro, Paz e Terra, 1987.

FREIRE, Paulo. Ação Cultural para a liberdade. 5 ed. Rio de Janeiro, Paz e Terra, 1987.

KERSTING, Wolfgang. Liberdade e liberalismo. Porto Alegre, EDIPUCRS, 2005.

LESSA, Sérgio. Lukács e a ontologia: uma introdução. Outubro, v. 5, n. 1, p. 89-100, 2001.

MAFRA, JASON F; CAMACHO, Carlos. M. P. Paulo Freire e o materialismo histórico: um estudo de “extensão ou comunicação?”. Revista Pedagógica, Chapecó, v. 19, n. 41, p. 118136, 2017 maio/ago.

MARX, Karl. A Ideologia Alemã. Tradução: Rubens Enderle, Nélio Schneider, Luciano Martorano. São Paulo: Boitempo, 2000.

MARX, K. O Capital - Livro I - crítica da economia política: O processo de produção do capital. Tradução Rubens Enderle. São Paulo: Boitempo, 2013. Disponível em: https://edisciplinas.usp.br/pluginfile.php/2547757/mod_resource/content/1/MARX\%2C\%20K arl.\%200\%20Capital.\%20vol\%20l.\%20Boitempo..pdf

SÃO PAULO (Estado) Secretaria de Educação. Proposta Curricular (Geral). Coord. Maria Inês Fini. São Paulo: SEE, 2008-a. 
REVISTA

Revista do Programa de Pós-Graduação em Educação da Unochapecó ISSN 1984-1566 (on-line) ISSN 1415-8175 (impressa)

SILVA, Marcelo Lira. Os Fundamentos do Liberalismo Clássico: A relação entre estado, direito e democracia. Revista Aurora, v. 5, n. 1, p. 121-147, 2011.

Recebido em: 01-03-2021

Aprovado em: 29-04-2021

Publicado em: 24-05-2021 